\title{
choer
}

\section{Neofascismo, "Nova República” e a ascensão das direitas no Brasil}

\author{
Odilon Caldeira Neto \\ Doutor em História pela Universidade Federal do Rio Grande do Sul \\ - UFRGS \\ Professor na Universidade Federal de Juiz de Fora - UFJF \\ Coordenador da Rede de Investigação "Direitas, História e Memória" \\ http://www.direitashistoria.net \\ odiloncaldeiraneto@gmail.com \\ https://orcid.org/0000-0001-5926-528X
}

\section{Resumo}

\begin{abstract}
Com a recente ascensão das direitas no Brasil, que culminou na eleição de Jair Bolsonaro, assim como de outros líderes da extrema direita, colocam-se em questão os impactos dessas novas formatações no campo político-partidário brasileiro e quais são os pressupostos e as filiações ideológicas. Além de categorias como "novas direitas", termos como "neofascismo" são utilizados indiscriminadamente para interpretar expressões e grupos dos mais distintos. A fim de colocar tais aspectos em questão, este artigo apresenta um apanhado das relações entre grupelhos neofascistas e forças político-partidárias no Brasil. Analisando desde a transição democrática até a eleição de Bolsonaro, investigaram-se as aproximações e disputas existentes entre grupelhos neofascistas e agremiações partidárias, a fim de compreender as diversas disputas existentes no campo da extrema direita brasileira ao longo da "Nova República".
\end{abstract}

Palavras-chave neofascismo; novas direitas; partidos políticos.

Conhecer: debate entre o público e o privado 2020, Vol. 10, no 24

ISSN 2238-0426

DOI https://doi.org/10.32335/2238-0426.2020.10.24.2060

Licença Creative Commons Atribuição (CC BY 4.0)

Data de submissão 29 set 19

Data de publicação 20 jan 20 


\title{
Neofascism, ‘New Republic’ and the rise of right-wing groups in Brazil
}

\begin{abstract}
With the recent rise of right-wing groups in Brazil, which culminated in Jair Bolsonaro's election, as well as in the election of other far-right-wing leaders, the impacts of these new arrangements in the Brazilian political and partisan field are put into question, besides which assumptions and ideological affiliations are at stake. In addition to categories such as 'new right-wing groups,' terms like 'neofascism' are used indiscriminately to interpret the most varied expressions and groups. In order to put these aspects into question, this article brings an overview of the relations between little neofascist groups and partisan political forces in Brazil. By analyzing from the moment of democratic transition until Bolsonaro's election, the relations and disputes between tiny neofascist groups and partisan groups were investigated, in order to see the various disputes existing in the Brazilian far right-wing throughout the 'New Republic.'
\end{abstract}

Key words neofascism; new right-wing groups; political parties.

\section{Neofascismo, “Nueva República” y el ascenso de las derechas en Brasil Resumen}

Con el reciente ascenso de las derechas en Brasil, que culminó en la elección de Jair Bolsonaro, así como en la elección de otros líderes de extrema derecha, se cuestionan los impactos de estas nuevas formaciones en el campo político-partidista brasileño y cuáles son los supuestos y las afiliaciones ideológicas. Además de categorías como "nuevas derechas", términos como "neofascismo" se usan indiscriminadamente para interpretar expresiones y grupos de los más distintos tipos. Para cuestionar estos aspectos, este artículo ofrece una visión general de las relaciones entre pequeños grupos neofascistas y fuerzas político-partidistas en Brasil. Al analizar desde el momento de la transición democrática hasta la elección de Bolsonaro, se investigaron las relaciones y disputas entre pequeños grupos neofascistas y grupos partidistas, para comprender las diversas disputas que existen en el campo de la extrema derecha brasileña a lo largo de la "Nueva República".

Palabras clave neofascismo; nuevas derechas; partidos políticos.

\section{Néofascisme, « Nouvelle République » et la montée des groupes de droite au Brésil}

\section{Résumé}

Avec la récente montée des groupes de droite au Brésil, qui a culminé avec l'élection de Jair Bolsonaro, ainsi que d'autres leaders de l'extrême droite, les impacts de ces nouvelles arrangements dans le champ politique et partisan brésilien sont remis en question, ainsi que quelles sont les hypothèses et affiliations idéologiques. Outre des catégories telles que "nouveaux groupes de droite ", des termes tels que " néofascisme » sont utilisés sans discernement pour interpréter des expressions et groupes les plus variés. Pour remettre en question ces aspects, cet article offre un aperçu des relations entre les petits groupes néofascistes et les forces politiques et partisanes au Brésil. En analysant depuis le moment de la transition démocratique jusqu'à l'élection de Bolsonaro, les relations et les différends entre les petits groupes néofascistes et les groupes partisans ont été étudiés, afin de comprendre les différents différends qui existaient dans le champ de l'extrême droite brésilienne tout au long de la « Nouvelle République ».

Mots-clés néofascisme; nouveaux groupes de droite; partis politiques. 


\section{Introdução}

\section{A ascensão conservadora e a questão neofascista}

Ao longo do processo da recente ascensão de forças conservadoras e autoritárias no Brasil, diversos termos foram adotados para classificar e interpretar esse fenômeno que, se não é absolutamente novo na história do Brasil republicano, decerto traz algumas novidades, inclusive em relação à sua intensidade e suas conquistas eleitorais. Entre tais termos, pode-se citar: a) onda ou maré conservadora; b) autoritarismo; c) bolsonarismo; d) neofascismo; e) novas direitas; f) extrema direita; g) direita radical; h) neoliberalismo; i) democracia iliberal; j) populismo etc.

De certa maneira, essa diversidade demonstra a preocupação de pesquisadores e intelectuais diante de um fenômeno bastante complexo e diversificado, assim como aponta que o fenômeno traz novos traços e antigas características. Não despropositadamente, o termo "novas direitas" ganhou força, mas sem que houvesse consenso absoluto sobre qual é o significado e a extensão dessa categoria. Podemos citar algumas das variadas interpretações (sem qualquer pretensão de sermos exaustivos nesse quesito).

Na análise de Camila Rocha (2018), a nova direita é um fenômeno amplo e complexo, com origens que não são necessariamente imediatas. O processo de formação da nova direita brasileira envolve desde questões relativas à oposição aos governos do Partido dos Trabalhadores (PT) até a contrariedade diante de determinadas agendas políticas, como a legalização do aborto, ou questões de costumes. Como demonstra Rocha (2018), mesmo grupos mais organizados, como o Movimento Brasil Livre (MBL) foram formados a partir da socialização e da interação de pequenos grupos precedentes, em relações que fortaleceram o senso de unidade e a socialização política, bem como a formação de uma identidade filosófica comum.

De acordo com Fábio Gentile (2018), a relação entre grupos neoliberais e a agenda política preconceituosa do então deputado e atual presidente Jair Bolsonaro se dá em torno da construção de estratégias políticas de ambas as partes. As agendas políticas neoliberais, construídas por meio de interações transnacionais, não são necessariamente assimiladas, elas demonstram movimentos de aproximação e disputas que são inerentes ao campo político.

Nesse campo tão plural e por vezes conflituoso da nova direita brasileira, alguns autores argumentam que a sociedade brasileira observa o fenômeno de depuração de outro fenômeno, da "direita envergonhada", que teve origem com o processo de transição democrática e o advento da chamada "Nova República”. Para Marcos dos Reis Quadros e Rafael Madeira (2018), esse processo foi impulsionado por diversas razões, inclusive pela 
formação de grupos parlamentares de perfil conservador, como a bancada da bala e a bancada evangélica.

$\mathrm{Na}$ interpretação de Martin Egon Maitino (2018), a atuação de políticos como Jair Bolsonaro auxiliou a compor esse processo de depuração, assim como o movimento e a formação de um novo campo da direita brasileira, caracterizada pela exaltação da ditadura civil-militar, seus crimes e, em especial o anticomunismo (e sua variação mais imediata, o antipetismo). Em certo sentido, dialoga com as impressões de Mateus Pereira (2015), que observa as "guerras de memória" em torno de eventos como a Comissão Nacional da Verdade, e a formação de uma rede de grupelhos de extrema direita impulsionada pelo negacionismo da mais recente ditadura brasileira.

De todo modo, pode-se afirmar que, a depender do foco de análise, há diversificadas novas direitas, não somente em relação ao ponto de partida, mas também aos elementos de unidade e identificação ideológica. Mesmo Antônio Flávio Pierucci (1987), em texto publicado ao final do processo de transição democrática, já demonstrava a constituição de uma "nova direita", fundamentada na negação dos direitos humanos e assentada na enunciação de identidades supostamente inconciliáveis.

Mesmo com a riqueza das variadas interpretações e certa polissemia na constituição do campo das novas direitas no Brasil, é comum observar (não necessariamente em meios especializados) a tentação de simplificar fenômenos tão complexos - e transnacionais - a partir de termos pouco apurados heuristicamente, como o neofascismo, tal qual utilizado em alguns casos. Ou, melhor dizendo, uma noção de neofascismo tão abrangente quanto conflituosa, que abarca categorias tão diversas no campo das direitas no Brasil, como grupos monarquistas, liberais radicais, conservadores, evangélicos, militaristas, armamentistas, neofascistas, e assim por diante.

De certa maneira, isso reflete não apenas a complexidade da questão, mas também as disputas políticas ou mesmo a influência de meios não especializados. Afinal, o termo fascismo (e neofascismo) também é um adjetivo político (Mann, 2008). Algo ligeiramente similar ocorreu ao longo das interpretações das ditaduras militares na América Latina - e em seu decurso -, que autores como Álvaro Briones (1975) viam como a construção de certo neofascismo como categoria a explicar aqueles regimes autoritários.

No entanto, já é plenamente consolidada a interpretação de que as ditaduras na América Latina, a despeito de proporcionarem a inserção de grupos e indivíduos fascistas, não se transformaram em qualquer espécie de regime neofascista (Boron, 1977). No caso brasileiro, inclusive, a despeito do intenso anticomunismo da ditadura iniciada em 1964, os antigos membros da Ação Integralista Brasileira (AIB) não obtiveram destaque e não conseguiram "fascistizar" o regime autoritário (Trindade, 2000). 
Em tempos mais recentes, sobretudo após a eleição de Jair Bolsonaro, esse debate voltou à tona. Algumas questões são eventualmente trazidas por especialistas ou indivíduos preocupados com o atual estágio da democracia brasileira:

- Estaria o Brasil sob um governo neofascista?

- Como indicam Guamán, Aragoneses e Martín (2019), o neofascismo atual, cujo representante brasileiro seria Bolsonaro, caracteriza-se por uma "estranha aliança" com o neoliberalismo internacional?

- Poderia o fascismo histórico, abertamente antípoda ao liberalismo, tornar-se congênere em sua versão atualizada?

A priori, considera-se que tanto o "neofascismo" quanto o próprio fascismo histórico não deve ser interpretado exclusivamente à luz de suas lideranças, mas sim de aspectos conjunturais que se encontram (e se constroem) com o culto à liderança e à mitologia política, forjando uma relação simbiótica entre líderes, Estado e nação. Em outras palavras, levamos em consideração que uma personalidade autoritária não constrói sozinha um regime autoritário ou um movimento fascista.

Dessa maneira, e levando em consideração que o neofascismo e a extrema direita, no Brasil, não são uma novidade recente, este artigo tem por objetivo realizar um apanhado da relação entre determinados grupos da extrema direita brasileira, notadamente os grupos de inspiração neofascista, e partidos políticos legalmente constituídos no país. O texto, sem pretensão de apresentar um levantamento exaustivo do tema, busca fornecer um panorama da relação entre grupos de extrema direita, em especial os grupelhos neofascistas, e partidos políticos, em um recorte temporal que cobre desde a transição democrática à posse de Jair Bolsonaro como Presidente da República.

Inclusive, essa iniciativa surge de uma constatação: desde o momento da transição democrática até o apogeu das novas direitas, a extrema direita brasileira não construiu um projeto político robusto, em termos de organizações partidárias, a enunciar valores ideológicos que possam aproximar-se das pretensões de grupelhos neofascistas.

Para isso, utilizamos uma definição mais restritiva de neofascismo, tal qual um tipo ideal, que o vê como grupelhos que almejam realizar reformulações e retomadas de um arquétipo baseado nas experiências dos movimentos e das ditaduras fascistas do entreguerras. Essa definição mais circunscrita de neofascismo decorre da necessidade de interpretar a historicidade desses grupelhos e suas relações com agremiações políticas, assim como seus interesses no fenômeno plural das novas direitas.

\section{Neofascismo, extrema direita e novas direitas}

Os tempos mais recentes no cenário político brasileiro evidenciam o crescimento da atividade de pequenas e médias organizações e, em especial, de um discurso e imaginário 
político de extrema direita, com capilaridade na sociedade. Permeados pela misoginia, em contrariedade às políticas sociais e de distribuição de renda, assim como o desprezo aos direitos humanos, esses agrupamentos partilham elementos de continuidade de uma cultura política autoritária, em que o anticomunismo é um elemento de engrenagem sistêmica, de culto à liderança e de escolha de "salvadores da pátria" (Girardet, 1996).

o "retorno", ou mais propriamente o crescimento, das atividades das porções mais radicais e antidemocráticas da direita brasileira é acompanhado pela preocupação de significativa parcela da opinião pública e de diversos acadêmicos (Velasco e Cruz, Kaysel, \& Codas, 2015). Sobretudo em momentos de crise de legitimidade e de ruptura institucional (intensificados a partir da destituição de Dilma Rousseff), ganham força algumas indagações quanto à natureza e capilaridade da extrema direita na atualidade brasileira, assim como seu poderio efetivo (e seu impacto) no campo político, em especial nas esferas institucionais.

O objetivo deste artigo é realizar um mapeamento das relações entre grupos e tendências da extrema direita brasileira com partidos políticos a partir do fim da transição democrática ou, em outras palavras, as estratégias da extrema direita ao longo da chamada "Nova República" até a atualidade e, em especial, suas relações com as agremiações partidárias. Desse modo, levam-se em consideração os partidos como elemento de mediação política, além da necessidade de interpretação da variável ideológica nos partidos, perspectiva que não exclui outros elementos, como questões macroeconômicas, alianças eleitorais, e assim por diante.

Essa abordagem está relacionada com a preocupação do afastamento de uma leitura mecanicista dos processos políticos e - em contrapartida e especialmente - a interpretação do anticomunismo, além do conservadorismo e do nacionalismo autoritário, como categorias fundamentais para pensar a extrema direita brasileira e as direitas latinoamericanas (Boisard, 2014; Motta, 2002). Ao trabalhar com essas categorias, temos um quadro de maior historicidade e menor imediatismo, o que possibilita uma leitura mais detalhada da relação entre grupos da extrema direita e partidos políticos, desde o fim da década de 1970 até os mais recentes processos eleitorais.

Ao longo das últimas décadas, não é despropositado afirmar que a direita brasileira é uma relativa incógnita. Afinal, transcorrida a existência institucional de uma ditadura construída a partir de bases civis e militares e de um regime de exceção que havia subjugado organizações políticas de diversos matizes - e em especial à "esquerda" do espectro político -, aparentemente, teria havido uma profunda e repentina modificação. Aos olhos de um observador externo, a sociedade brasileira (sobretudo a classe política e as elites dirigentes), seria possivelmente caracterizada como portadora de uma espécie de "vocação democrática". 
De fato, essa questão não seria fruto de qualquer casualidade histórica. Como sugeriu Daniel Aarão Reis (2010), criara-se, ao longo da lenta e gradual transição democrática, mas também em torno do processo da Assembleia Nacional Constituinte, a impressão de um consenso democrático e, sobretudo, antiautoritário que, em tese, seria a representação dessa própria sociedade. Logo, a condição democrática era o efetivo resultante da maioria absoluta dos cidadãos brasileiros, de modo que o apoio civil ao golpe e à continuidade do regime de exceção seria uma espécie de lapso, fruto de relações conturbadas, inclusive entre civis e militares.

Dessa maneira, estabeleceu-se um processo de silenciamento coletivo (e uma suposta consensualidade democrática), que incluía não apenas a sociedade civil em torno desse pacto, mas também as elites e as classes dirigentes, além de alguns setores oposicionistas. É necessário ressaltar que esse processo ocorreu não apenas na dimensão de uma espécie de imaginário coletivo que pairava sobre a sociedade civil, mas teve implicações diretas na ossatura da chamada "Nova República" e em sua transição conservadora - em linhas gerais, é esse o aspecto delineado em Power (2000). Seja em termos da inexistência de implicações legais aos agentes envolvidos no regime de exceção e em suas práticas persecutórias ou da permanência dessas elites e de seus atores nas altas instâncias do poder, ainda que sob roupagens democráticas ${ }^{1}$.

É nesse contexto que se estabelece a problemática da extrema direita e da relação dela com os partidos políticos. O momento de abertura do campo político ao longo dos capítulos finais da transição democrática coincide com uma relativa pulverização de diversas pequenas organizações da extrema direita, que buscavam relacionar-se com a abertura das possibilidades do campo político, todavia, com um ambiente fortemente refratário. A partir desse quadro, pode-se observar as estratégias, em especial durante os processos eleitorais e a relação com partidos políticos.

No final da década de 1970, com a revogação do Ato Institucional n. 5 (1968), além do fim do sistema bipartidário, teve início o processo de abertura política. Nesse momento, iniciaram-se as movimentações de pequenas organizações da extrema direita, que visualizavam a organização de legendas partidárias como instrumento de disputa nesse contexto de abertura política, inclusive em torno do processo da Assembleia Constituinte (Dreifuss, 1989).

O integralismo brasileiro - principal organização fascista latino-americana - embora sem a liderança de Plínio Salgado (falecido em 1975), persistiu como um dos principais referenciais políticos, em grande parte por ter sido a primeira organização política de massa da história brasileira, assim como o principal movimento fascista fora do continente europeu. Além disso, os integralistas tiveram relação, ainda que de modo coadjuvante, com

\footnotetext{
1 Essa não foi, claro, uma especificidade brasileira em termos das transições "por transação", ou transições "contínuas". Em relação a esse tópico, ver Costa Pinto e Martinho (2003).
} 
a implantação do regime autoritário em 1964. Ao longo da década de 1980, as tratativas não efetivadas em torno da fundação do Partido de Ação Nacionalista (PAN) foi o principal instrumento de orientação integralista em relação aos partidos políticos (Natali, 1986).

Inspirado na tríade "Deus, Pátria e Família" dos tempos de AIB, parte da militância integralista defendia a construção do PAN como "instrumento político capaz de preservar as magnas conquistas da civilização brasileira, desde o seu marco inicial - a Santa Cruz" (Partido de Ação Nacionalista, 1983, p. 1). O grupo se apresentava como representante autêntico do nacionalismo brasileiro e tinha como princípios fundamentais a luta contra a "ameaça do imperialismo estrangeiro (comunista ou capitalista)" (Partido de Ação Nacionalista, 1983, p. 3), em consonância com o discurso anticomunista e antiliberal integralista da década de 1930.

Uma das propostas do grupo era a construção de uma terceira via no plano econômico e político, baseada na Doutrina Social da Igreja e em conformidade com os princípios do corporativismo integralista ${ }^{2}$. No entanto, os momentos que antecederam as eleições presidenciais de 1989 marcaram, na realidade, a intensificação da fragmentação da extrema direita brasileira, seja pela disputa por representatividade ou por questões de fundo ideológico, bem como o surgimento de novas organizações. Os integralistas, além da fundação do PAN, conjecturavam a criação do Partido de Ação Integralista (PAI), evidenciando as disputas internas sobre quem deveria ser o sucessor de Plínio Salgado (Integralista sonha com partido, 1988), ou até se deveria ocorrer a refundação da sigla AIB.

No contexto de definição das candidaturas presidenciais, era evidente que as porções mais radicais da direita brasileira não tinham um projeto político uníssono, inclusive em termos de organização, tampouco um candidato que as representasse. A extrema direita de inspiração fascista estava dividida em pequenas organizações, como: a) Ação Nacionalista; b) Partido Nacional-Socialista Brasileiro; c) Partido Nacional Revolucionário Brasileiro; d) Movimento Pátria e Liberdade; e) Ação Integralista Brasileira; f) Movimento Pátria Livre; g) Frente Nacionalista; h) Ação Nacionalista Democrática (ANDE) (Direita luta pela "boquinha", 1989) etc.

Dentre essas organizações, a ANDE foi uma das que tentaram aglutinar as diversas siglas da extrema direita no período. Liderada por Raphael Noschese e João Marcos Flaquer, antigos líderes de grupos juvenis e estudantis atuantes na ditadura ${ }^{3}$, pleiteavam a criação de uma sigla para agregar os diversos grupos dispersos (Direita articula-se com objetivo de influir na sucessão, 1989). A despeito da tentativa de criação de uma possível plataforma política comum, o grupo também tentou delinear escolhas em relação a candidaturas que, porventura, representassem os interesses do grupo. Os nomes aventados foram

2 Em relação aos projetos do corporativismo e dos modelos do "Estado Integral”, ver Gonçalves e Caldeira (2016).

3 Raphael Noschese foi líder do grupo denominado "Movimento Estudantil Democrático”, organização que atuou no processo de agitação política que antecedeu o golpe de 1964. Já João Flaquer havia sido a principal liderança do "Comando de Caça aos Comunistas" (CCC). 
Jânio Quadros (de perfil conservador, que acabou por não se candidatar à presidência) e Guilherme Afif Domingos (Jânio e Afif são as opções da direita para a presidência, 1989), do Partido Liberal (PL), que esteve filiado ao Partido Democrático Social (PDS) durante a ditadura.

De qualquer maneira, é necessário ponderar que a ANDE teve atuação inócua na tentativa de estabelecer articulações entre os setores radicais da direita brasileira ou mesmo na definição de uma candidatura representativa desses diversos pequenos grupos. Em relação ao apoio às candidaturas existentes em 1989, o nome de Ronaldo Caiado ganhou força em alguns setores, inclusive em grupos integralistas (Direita luta pela "boquinha", 1989). Uma das razões para o apoio residia na atividade extraparlamentar de Caiado diante da União Democrática Ruralista (UDR) que, além de defender a propriedade e os interesses dos grandes proprietários de terra, combatia - inclusive com violência - os movimentos de reivindicações no campo, em especial o Movimento dos Trabalhadores Rurais Sem Terra (MST).

Apesar da definição de apoio a determinado candidato, o contexto da extrema direita brasileira em meados de 1989 era de intensa fragmentação e de mero coadjuvante político. Além da reminiscência do passado autoritário e do fenômeno da "direita envergonhada", pode-se ponderar que o surgimento de novas siglas, assim como a radicalização de alguns desses grupos, ajudou a fomentar esse caráter desarticulado.

A partir da década de 1980, intensificou-se no Brasil a ação de diversos grupos neonazistas. É possível definir três tendências nas configurações do neonazismo no início da "Nova República" (Gonçalves, Caldeira, \& Andrade, 2017). A primeiro delas consistia em agrupamentos juvenis urbanos, em especial os skinheads (ou naziskin), caracterizados pelo apelo às práticas e estéticas da violência ritualizada, principalmente na perseguição às minorias (lésbicas, gays, bissexuais, travestis, transexuais e transgêneros [LGBTs], nordestinos, judeus etc. $)^{4}$.

Além dessa tendência mais violenta, as publicações negacionistas do holocausto, que circulavam por meio da Editora Revisão (fundada em Porto Alegre, em 1985) (Jesus, 2006), compunham a parte mais significativa de difusão do antissemitismo na extrema direita no período, além do princípio de articulação entre as demais organizações, em especial com alguns dos grupos integralistas (Caldeira, 2014).

Por meio da literatura negacionista e de obras como Holocausto: judeu ou alemão? (Castan, 1985) - de Siegfried Ellwanger Castan, proprietário da Editora Revisão -, em torno

4 A facção neonazista dos skinheads, no Brasil, é caracterizada em especial pelo seu caráter grupuscular - pequenos agrupamentos, com vida relativamente curta e um cerne ideológico baseado no anticomunismo, antissemitismo e na defesa da superioridade racial branca (e europeia). Surgido em São Paulo na década de 1980, evidencia-se, com o passar dos anos, a intensificação dessa desvinculação das correntes do neonazismo das tendências da extrema direita brasileira, de modo que se aprofunda a relação de cooperação com alguns agrupamentos atuantes em países vizinhos (em especial a Argentina e o Chile), assim como em Portugal e nos Estados Unidos da América (EUA) (cf. Almeida, 2017). 
dos discursos de negação do holocausto e de resgate do nacional-socialismo, havia a interlocução com grupos skinheads - como os white power (Almeida, 2004) -, além de estratégias de fomento a organizações partidárias.

O Partido Nacional-Socialista Brasileiro (PNSB) e o Partido Nacionalista Revolucionário Brasileiro (PNRB) foram as 2 organizações de orientação neonazista em vias de articulação na década de 1980. Liderados por Armando Zanini Jr. (Lopes, 1992), um oficial da reserva da Marinha Mercante, as 2 pequenas agremiações defendiam a prática do eugenismo, a partir da necessidade de formação de uma autêntica "raça brasileira", sobretudo baseada na exclusão da presença judaica na nação e em seu éthos.

As duas agremiações, sem qualquer protagonismo mesmo no campo da extrema direita, não chegaram a obter o reconhecimento do registro partidário pelo Tribunal Superior Eleitoral (TSE). Além disso, a relação entre grupos mais radicais - como os skinheads, assim como os projetos partidários de Armando Zanini - e outras organizações (em especial com alguns grupos integralistas) era articulada com grande ressalva, seja pelo radicalismo do discurso, a evidente intolerância ou mesmo pelo caráter ilegal dessas organizações, em especial devido ao antissemitismo negacionista ${ }^{5}$.

Além dessas tendências mais radicais, vinculadas de formas diversas às experiências do fascismo histórico, outra parcela significativa da extrema direita, durante os anos 1980, eram os grupos vinculados aos militares (da reserva e da ativa) e civis, que se articulavam, por exemplo, mediante periódicos como Letras em Marcha, Inconfidência e Ombro a Ombro (Santos, 2009), e que rotineiramente denunciavam a "comunização" da nação brasileira, lavagem cerebral, durante o processo de transição ("Letras em Marcha” aponta comunização, 1986).

Em Ombro a Ombro, fundado em 1988 por ex-membros da Escola Superior de Guerra (ESG) e da Associação de Diplomados da Escola Superior de Guerra (ADESG), é evidente o processo de tentativa de articulação dos interesses militares em torno do processo de transição democrática e, em especial, da corrida eleitoral. Um dos aspectos centrais em Ombro a Ombro e nos demais periódicos era a batalha pela memória do golpe de 1964, dimensionada pelo processo de transição, mas também as tensões entre militares, classe política e sociedade civil, inclusive a partir das discussões em torno dos processos dos crimes da ditadura (Cardoso, 2011).

Em relação aos partidos políticos e ao processo eleitoral, no desenrolar das eleições de 1989, foi marcante a preocupação com o avanço do campo da esquerda, em especial nas candidaturas de Leonel Brizola (do Partido Democrático Trabalhista [PDT]) e de Luís

$5 \quad$ A partir de 1986, inicia-se uma disputa judicial envolvendo, de um lado, os negacionistas (em especial a Editora Revisão e Siegfried Ellwanger Castan), contra grupos em defesa dos direitos humanos, associações judaicas e movimentos antirracistas. A disputa, iniciada nas cortes locais de Porto Alegre, chegou até o Supremo Tribunal Federal (STF), com a proibição da veiculação das obras da Editora Revisão (cf. Caldeira, 2009). 
Inácio Lula da Silva (do PT), mas não na promoção de uma candidatura presidencial que representasse os setores mais à direita dos militares da ativa e da reserva.

De fato, a única definição evidente viria a ocorrer apenas no limiar do segundo turno das eleições presidenciais de 1989, em que Fernando Collor de Mello (do Partido da Reconstrução Nacional [PRN]) é descrito como capaz de romper o avanço do "candidato que representa o velho e ultrapassado [...] que reduz tudo a um confronto entre pobres e ricos; entre capital e trabalho" (Momento decisivo, 1989).

Em linhas gerais, pode-se afirmar que, do momento em que se constituiu o processo de transição democrática até o processo de delineamento das primeiras eleições para Presidente da República, em 1989, o cenário da extrema direita brasileira foi de grande ramificação e desarticulação. Ao passo que algumas expressões buscam articular-se na expressão de lideranças políticas ligeiramente consagradas (como Jânio Quadros), outras buscam articular-se nos referenciais em contrariedade aos movimentos sociais de esquerda (como Ronaldo Caiado). Em outros momentos, a figura da liderança emergente (Fernando Collor) é tomada como instrumento de garantia dos interesses de combate ao "avanço comunista".

De qualquer modo, embora não tenha ocorrido uma articulação efetiva em torno de uma candidatura, assim como o impacto político da extrema direita nessa conjuntura era diminuto, torna-se evidente a existência de um princípio de articulação entre esses pequenos agrupamentos, além da tentativa de ampliação de um espaço político. Em primeiro lugar, tratava-se da necessidade de articulação em uma nova conjuntura, marcada pela ampliação das possibilidades (candidaturas, legendas, espaços de atuação como grupos de pressão), mas que deveria articular-se em um contexto de crítica aos autoritarismos de direita, ou mesmo com o final da Guerra Fria, que ajudava a tipificar o binarismo característico no discurso desses grupos.

Há, contudo, um processo de evidência dos valores fundamentais para essas parcelas da extrema direita brasileira, baseado no partilhar de uma visão crítica ao processo de transição democrática, quanto ao perigo do avanço das forças de esquerda, bem como a necessidade de difusão de um ideal conservador, pautado pelo nacionalismo e pela presença de um Estado autoritário. Em relação ao Estado, poderia variar desde a finalidade de repressão aos movimentos sociais até a intervenção na economia e as relações de trabalho.

A partir de 1989, em especial após a campanha eleitoral, a relação da extrema direita com os partidos políticos em torno da representatividade e influência se modifica de modo significativo. O médico Enéas Ferreira Carneiro, que não tivera qualquer trajetória política pretérita, liderou a formação do Partido de Reedificação da Ordem Nacional (PRONA) em 1989, no mesmo ano em que se lançou como candidato à Presidência da República. 
Embora contasse com somente 15 segundos no Horário Político Eleitoral Gratuito, Enéas Carneiro criticava a Assembleia Constituinte, o profissionalismo político e as campanhas eleitorais profissionais, assim como proclamava o voto em seu nome a partir de frases como:

Se o senhor acreditou em mim, proteste contra tudo isso que ai está. Vote no fim da desordem! No dia quinze, respire fundo, encha o seu peito de ar, e grite junto com todo o Brasil: Meu nome é Enéas!

O slogan "Meu nome é Enéas", aliado ao teor de descontentamento político, foi um elemento de destaque em uma campanha eleitoral presidencial com mais de 20 candidatos. Além disso, o fato de Enéas Carneiro (e o PRONA) se apresentar como sujeito alienígena diante do processo de profissionalização política, foi um dos ingredientes de construção de uma narrativa política de outsider - que alçou o candidato à fama. Por fim, o discurso autoritário, o elogio à ordem e a denúncia de uma crise moral e de costumes (Partido de Reedificação da Ordem Nacional - PRONA - Ata de Fundação, 1989) ajudaram a reservar uma vaga no campo conservador, também agradando diversos setores da extrema direita (Caldeira, 2016a).

No entanto, o crescimento do PRONA como partido referencial da extrema direita brasileira não deve ser entendido apenas como uma relação mecanicista entre o discurso da liderança e os anseios de setores do campo político. Em primeiro lugar, é necessário compreender a existência de uma vaga não preenchida no campo da direita brasileira, construída inclusive a partir do processo de transição democrática.

O processo de fortalecimento político do PRONA, após 1989, coincide com dois elementos conjecturais. O primeiro deles seria a crise política desencadeada após o impeachment de Fernando Collor de Mello, em que a figura de outsider representaria uma crítica à profissionalização política e uma alternativa ao descontentamento gerado pela queda do primeiro presidente eleito pelo voto direto após o fim do regime militar. Além disso, o desenvolvimento de novas políticas econômicas alinhadas ao Consenso de Washington, especialmente o Plano Real, constituiu alvo de críticas diversas à esquerda e à direita.

$\mathrm{Na}$ expressão politicamente organizada da direita, coube ao PRONA se articular com diversas tendências existentes, refinando seu discurso, em que o apelo à ordem e à autoridade se coadunava com a denúncia de uma conspiração a destruir a soberania nacional ${ }^{6}$. A defesa de um Estado forte, técnico e interventor passaria a ser não apenas uma

6 Esse seria o mote não apenas das campanhas eleitorais, mas também do Programa de Governo do PRONA (cf. Carneiro, 1994). 
carta de apresentação do PRONA a diversos representantes da extrema direita brasileira, mas um resultado efetivo dessa interação.

Entre 1989 e a preparação para as eleições de 1994, o PRONA intensificou a relação com alguns núcleos políticos do nacionalismo autoritário, em especial aqueles que colaboravam com o jornal Ombro a Ombro, de onde viriam diversos colaboradores do programa de governo de 1994, em áreas como economia, estratégia, geopolítica e questões minerais, como era o caso do contra-almirante Roberto Gama e Silva, candidato à vice-presidência ao lado de Enéas Carneiro.

Outros grupos da extrema direita declararam apoio à candidatura de Enéas Carneiro, como alguns grupos skinheads - autoritários, mas abertamente não racistas (Vale, 1994) -, e especialmente Armando Zanini, na condição de presidente do Partido Nacionalista Revolucionário Brasileiro (PNRB) (Mack, 1994). Apesar desses apoios não terem sido reconhecidos oficialmente pelo PRONA, ilustram o grau de representatividade conquistado pela agremiação, assim como certo padrão da movimentação de grupos neofascistas em relação ao campo político institucional.

Nas eleições de 1994, Enéas Carneiro obteve o terceiro lugar, com 7,38\% ${ }^{7}$ dos votos válidos, de modo que o "perigo Enéas" foi considerado um risco de ascensão do (neo) fascismo. Independentemente da caracterização do ideário político de Enéas Carneiro e do PRONA - que estavam mais próximos ao nacionalismo autoritário e conservador do que propriamente do (neo)fascismo ou do integralismo -, a relação com organizações da extrema direita se intensificou nas futuras candidaturas.

Em 1998, ano da última candidatura presidencial de Enéas Carneiro, a relação com pequenos grupos se fortaleceu, fosse com organizações conservadoras de combate ao aborto ou com organizações como o Movimento de Solidariedade Ibero-Americana principal braço das organizações de Lyndon LaRouche no Brasil (Krischker, 2004) -, intensificando o teor conspiracionista das candidaturas do líder do PRONA.

Embora o PRONA tenha se consolidado como principal referencial da extrema direita, sua relação com grupos integralistas só viria a se intensificar a partir dos anos 2000, em razão do hiato institucional dos grupos integralistas, em decorrência das disputas de poder e de concepções ideológicas diante de temáticas problemáticas - como o antissemitismo e o negacionismo (Caldeira, 2014) -, ou de questões estratégicas. De qualquer modo, o PRONA permaneceu como principal referência institucional da extrema direita brasileira até 2006, quando o partido foi extinto.

A partir de 2002, o cenário político brasileiro se modificou com a vitória do PT e a ascensão de diversos governos de esquerda na América Latina. Embora o PRONA se encontrasse em sua fase final, observa-se cooperação entre as lideranças parlamentares

7 Ou exatos 4.670.894 votos, segundo dados do TSE. 
do partido e os setores da direita, em especial nas reivindicações relativas aos processos das batalhas de memória do regime militar, ocasionando inclusive a aproximação entre deputados do partido e outras lideranças da extrema direita, como o militar reformado e então deputado federal, Jair Bolsonaro ${ }^{8}$.

Com o fim do PRONA, abriu-se uma vaga em termos de representatividade da extrema direita brasileira, mas o contexto se tornou diversificado. Seja pela continuidade dos governos do PT até a destituição de Dilma Rousseff, em 2016 ou em relação ao contexto latino-americano. Além disso, é necessário ponderar a existência de outras variáveis, como a relação do conservadorismo evangélico (e não apenas de organizações católicas) com a extrema direita mais recente.

As atividades da Comissão Nacional da Verdade (criada em 2011 e institucionalizada em 2012) intensificaram a reação de setores militares de direita, em especial das tendências mais radicais (Pereira, 2015). Organizações como o Terrorismo Nunca Mais (Ternuma) passaram a reivindicar narrativas contestatórias aos relatórios dessa comissão, assim como a defesa de projetos políticos alternativos.

É nesse bojo que passa a ser idealizada a refundação da "Aliança Renovadora Nacional" (Caldeira, 2013), partido de sustentação à ditadura iniciada em 1964, bem como a formação do Partido Militar Brasileiro (PMIB), que se anuncia como "a solução para endireitar o país". Nessa conjuntura, as ações do partido (em formação) são anunciadas, mais uma vez, como estratégias contra o avanço do comunismo no Brasil.

Com o aprofundamento da crise política, algumas siglas até então sem grande relevância, como o Partido Renovador Trabalhista Brasileiro (PRTB) - e sua principal liderança, Levy Fidelix -, passaram a sinalizar uma guinada à direita radical a partir de 2014. Para tal, fomentaram a relação com tendências mais radicais, inclusive com grupelhos neofascistas, como a Frente Nacionalista. A Frente Nacionalista, fundada em Curitiba, enunciava inspiração tanto no integralismo de Plínio Salgado como no fascismo italiano e nas organizações de Oswald Mosley, além das formas de atuação de grupos neofascistas em diversas localidades, como Ucrânia, Itália e França. Além disso, o PRTB ensejou potenciais relações com alguns pequenos agrupamentos skinheads (Caldeira, 2016b), no entanto, o impacto midiático negativo arrefeceu essas cooperações de modo significativo.

O processo eleitoral que consagrou a vitória de Jair Bolsonaro atrelou, por consequência, o PRTB à chapa vitoriosa, tendo em vista que Hamilton Mourão, general da reserva e atual vice-presidente, é filiado a esse partido. Ao longo da campanha eleitoral de 2018, o PRTB de São Paulo se aproximou efetivamente da Frente Integralista Brasileira (FIB), principal organização neointegralista em atuação no país. Victor Barbuy, presidente

8 O Projeto de Lei n. 5.508, de 2005, que previa a inscrição de um militar morto em combate com a "Vanguarda Popular Revolucionária" no livro de heróis da Pátria, foi redigido em conjunto por Jair Bolsonaro e o deputado Elimar Máximo Damasceno, do PRONA 
da FIB, reuniu-se publicamente com Rodrigo Tavares, candidato ao Governo do Estado de São Paulo pelo PRTB, e com Levy Fidelix, presidente da sigla (Frente Integralista Brasileira, 2019). Em ambas as ocasiões, os líderes da FIB e do PRTB portavam exemplares de livros do líder máximo da AIB.

No entanto, a despeito do apoio de grupos neofascistas ao partido que compunha a coalizão vitoriosa de Jair Bolsonaro (PRTB e Partido Social Liberal [PSL]), não há indícios que atestem a proeminente participação de grupos neofascistas (no tipo ideal proposto) na construção da militância ou das redes sociais bolsonaristas. A isso é possível, ainda que a priori, tecer alguns comentários.

Sem dúvida, Bolsonaro era um representante de parcelas mais radicais da extrema direita brasileira. Figura politicamente ativa desde o período da transição democrática, Bolsonaro se notabilizou pela defesa da tortura e de outras atividades incompatíveis com a legalidade democrática, fomentando a descrença na democracia liberal, nos ritos institucionais, no desprezo às minorias e na perseguição política aos adversários. Dessa maneira, não é de espantar que o então deputado Jair Bolsonaro tenha sido reconhecido como uma possível liderança por grupos mais radicais da extrema direita brasileira, inclusive de inspiração neonazista (Oliveira, 2014).

Contudo, sob a retórica anticomunista e as premissas radicais e intolerantes, Jair Bolsonaro e seus aliados eram, até muito recentemente, quadros representativos do chamado "baixo clero", isto é, parlamentares sem grande expressão ou poderio político. Isso ocorria mesmo em termos de representatividade e relação com organizações neofascistas, o que, como mencionado, privilegiou o PRONA e Enéas Carneiro, inclusive pela existência de um partido político mais estruturado.

O vertiginoso fortalecimento da candidatura de Jair Bolsonaro à presidência em 2018 conviveu, no entanto, com a inexistência de uma máquina partidária robusta, ora sinalizando ao Partido Ecológico Nacional (PEN - que mudaria de sigla para PRONA, em homenagem a Enéas Carneiro, ou Patriotas), ou mesmo ao Partido Social Livre (PSL), agremiação que até recentemente não era dotada de uma agenda ideológica plenamente definida.

A hipótese e o argumento que aventamos é que, mais do que a existência de um padrão de articulação de grupos neofascistas ao longo da experiência da chamada Nova República, a movimentação das novas direitas ajuda a interpretar de modo mais efetivo a formação de um "bolsonarismo". Isto é, as organizações neofascistas passam a se aproximar de Bolsonaro - e do bolsonarismo - durante sua fase de crescimento e as agitações das novas direitas, mas o bolsonarismo não é fruto direto das articulações de grupos neofascistas, inclusive porque tais grupelhos não são dotados de expressiva força política.

Além disso, é necessário levar em conta que, ao longo do processo eleitoral, o discurso de campanha de Jair Bolsonaro sinalizava o esvaziamento do Estado, não apenas 
em sua dimensão social, mas inclusive sob o ponto de vista da privatização de empresas estatais em setores estratégicos que, na retórica e no imaginário nacionalista de direita, são essenciais para a manutenção da soberania nacional.

A despeito dos valores preconceituosos e intolerantes expressos por Jair Bolsonaro, alguns elementos de seu projeto político representam a diversidade das novas direitas no Brasil, inclusive em termos de miscelânea. As teorias da conspiração (como o "globalismo" ou o "marxismo cultural"), embebidas diretamente de um imaginário que impregnou diversos setores do pensamento de direita (e também do próprio fascismo histórico), coexistem com um projeto e discurso ultraliberal na economia, assim como o apoio a Israel e aos Estados Unidos da América (EUA), sobretudo nos projetos políticos de Benjamin Netanyahu e Donald Trump. Sob esse ponto de vista, embora o discurso e a prática de Jair Bolsonaro façam jus a algumas ideias-força da extrema direita brasileira de inspiração neofascista, em outros momentos oferece pontos de ruptura, ou ao menos diferenças substanciais, como é o caso da defesa das privatizações.

Não apenas por disputas entre representantes de um campo específico, qual seja, a extrema direita brasileira, mas também por questões filosóficas e ideológicas, as aproximações ou os apoios de grupos neofascistas a determinados aspectos de Jair Bolsonaro devem ser analisados à luz dos interesses desses grupos neofascistas, bem como de suas similaridades e diferenças. No entanto, afirmar as diferenças não deve significar o apagamento das similaridades entre os partidários de Bolsonaro, do fascismo histórico e também dos grupos neofascistas.

De qualquer maneira, desde a consolidação de uma retórica conservadora durante a queda de Dilma Rousseff, em 2016 (e não apenas a ascensão de Jair Bolsonaro), constata-se o fortalecimento de um sentimento mais propício à extrema direita, todavia, sem a existência de uma agremiação política de inspiração fascista a canalizar tal "potencial".

\section{Considerações finais}

De modo geral, observa-se que, desde o fim da transição democrática até tempos mais recentes, a extrema direita brasileira - em especial os grupos neofascistas - varia de atitude em relação ao campo político institucionalizado e, em particular, aos partidos políticos. No entanto, essa condição deve ser interpretada a partir de variáveis endógenas e exógenas, relacionadas não apenas ao campo do radicalismo de direita, mas também diante de aspectos conjecturais em nível nacional e internacional.

O período inicial é fortemente marcado não apenas pela desarticulação entre pequenos agrupamentos (e que, a despeito de suas similaridades, buscam estratégias e interesses diversificados), mas, sobretudo, pelo ambiente político refratário ao nacionalismo e ao 
autoritarismo de direita. O contexto da "direita envergonhada" foi, apesar da existência de uma transição conservadora, fundamental para arrefecer as tentações da extrema direita.

As modificações observadas devem ser interpretadas, em contrapartida, por meio da conjugação de um contexto nacional mais propenso à atuação de uma agremiação afeita aos discursos da extrema direita. Em primeiro lugar, a existência de uma crise política e de representatividade (institucionalizada no impeachment de Fernando Collor), mas também a intensificação dos processos de privatização. O perigo passa a ser não só o avanço das forças de esquerda, mas a própria garantia da soberania nacional diante dos interesses internacionais.

Já ao longo do período de relativa hegemonia das forças de esquerda no contexto nacional, mas também no latino-americano, observa-se o discurso de reação às pautas progressistas e, em especial no Brasil, as tentativas de discussão relativas aos legados autoritários que persistem em torno do processo de transição conservadora. Nessa conjuntura, a ruptura institucional, bem como os impactos de uma crise econômica de amplitude internacional, passa a ser um ingrediente de articulação de tendências da extrema direita que, embora sem a representatividade de uma agremiação específica canalisadora, busca tensionar o campo político a partir de plataformas e enunciados antidemocráticos.

Desse modo, embora pareça equivocado falar em continuidade e cooperação absoluta nos campos radicais da direita brasileira ao longo das últimas décadas, também seria equivocado afirmar a inexistência de uma relativa historicidade nos fenômenos mais recentes. Um dos pontos necessários a considerar nas agitações entre grupos neofascistas e a recente ascensão das direitas radicais no Brasil é a permanência de alguns pontos, que podemos considerar imaginários políticos ou culturas políticas, tendo em vista inclusive as dinâmicas de transmissão e os diálogos entre diferentes gerações de pessoas, grupos sociais e organizações políticas.

Concordamos com a interpretação de autores como Boisard (2014), segundo a qual o anticomunismo é um elemento que consolida uma genealogia e uma interligação para analisar apropriadamente o pensamento das direitas - em especial das direitas radicais - na América Latina. Evidentemente, entre os contextos de Guerra Fria e a escalada das novas direitas, os tempos são muitos diversificados.

Por fim, cabe a seguinte pergunta:

- Não será necessário interpretar essas questões de acordo com sua historicidade e diversidade, para além de categorias como o neofascismo, que podem constituir armadilhas interpretativas?

Nossa aposta é que sim. 


\section{Referências bibliográficas}

Almeida, A. (2004). Skinheads: os "mitos ordenadores" do poder branco paulista (Dissertação de Mestrado). Pontifícia Universidade Católica de São Paulo, São Paulo, SP.

Almeida, A. (2017). Música skinhead white power brasileira: guia de referência (Tese de Doutorado). Universidade de São Paulo, São Paulo, SP.

Ato Institucional n. 5, de 13 de dezembro de 1968. (1968). São mantidas a Constituição de 24 de janeiro de 1967 e as Constituições Estaduais; O Presidente da República poderá decretar a

intervenção nos estados e municípios, sem as limitações previstas na Constituição, suspender os direitos políticos de quaisquer cidadãos pelo prazo de 10 anos e cassar mandatos eletivos federais, estaduais e municipais, e dá outras providências. Brasília, DF.

Boisard, S. (2014). Pensando as direitas na América Latina: objeto científico, sujeitos e temporalidades? Varia História, 30(52), 85-100.

Boron, A. (1977). El fascismo como categoría histórica: en torno al problema de las dictaduras en América Latina. Revista Mexicana de Sociología, 39(2), 481-528.

Briones, A. (1975). El neofascism em América Latina. Problemas del Desarrollo, 6(23), 25-50.

Caldeira, O.. Neto, (2009). Memória e justiça: o negacionismo e a falsificação da história. Antíteses, 2(4), 1097-1123.

Caldeira, O.. Neto, (2013). A direita que se (re)cria: AIB, Arena e PRONA. Boletim do Tempo Presente, 4, 1-19.

Caldeira, O.. Neto, (2014). Sob o signo do sigma: integralismo. neointegralismo e antissemitismo. Maringá, PR: Ed. UEM.

Caldeira, O.. Neto, (2016a).“Nosso nome é Enéas!'”: Partido de Reedificação da Ordem Nacional (1989-2006). (Tese de Doutorado). Universidade Federal do Rio Grande do Sul, Porto Alegre, RS.

Caldeira, O.. Neto, (2016b). Frente Nacionalista, neofascismo e "novas direitas" no Brasil. Faces de Clio, 2(4), 20-36.

Cardoso, L. C. (2011). Os discursos de celebração da "Revolução de 1964". Revista Brasileira de História, 31(62), 117-140.

Carneiro, E. F. (Org.). (1994). Um grande projeto nacional: Enéas Presidente. [S.I.]: Partido de Reedificação da Ordem Nacional.

Castan, S. E. (1985). Holocausto: judeu ou alemão? Nos bastidores da mentira do século. Porto Alegre, RS: Revisão.

Costa Pinto, A., \& Martinho, F. C. P. (2003). O passado que não passa: a sombra das ditaduras na Europa do Sul e na América Latina. Rio de Janeiro, RJ: Civilização Brasileira. 
Direita articula-se com objetivo de influir na sucessão. (1989, 1ํ de março). In Folha de S. Paulo (p. A7).

Direita luta pela "boquinha". (1989, abril). In Ponto de Vista (CEFURIA), 15, 2.

Dreifuss, R. (1989). O jogo da direita na Nova República. São Paulo, SP: Vozes.

Frente Integralista Brasileira. (2019). FIB. Recuperado de https://www.integralismo.org.br/?

cont $=780 \&$ ox $=195 \# . X Y 7 F 8$ ubMNgU

Gentile, F. (2018). A direita brasileira em perspectiva histórica. Plural: Revista do Programa de Pós-Graduação em Sociologia da USP, 25(1), 92-11.

Girardet, R. (1996). Mitos y mitologías políticas. Buenos Aires, Argentina: Nueva Visión.

Gonçalves, L. P., \& Caldeira, O.. Neto (2016). Brazilian integralism and the corporatist intellectual triad. Portuguese Studies, 32(2), 225-243.

Gonçalves, L. P., Caldeira, O.. Neto, \& Andrade, G. I. F. (2017). Neonazismo e transição democrática: a experiência brasileira. Anuario IEHS, 32(2), 221-240.

Guamán, A., Aragoneses, A., \& Martín, S. (2019). Neofascimo: la bestia neoliberal. Madrid, España: Siglo XXI.

Integralista sonha com partido. (1988, 3 de maio). In Jornal do Brasil (p. 2).

Jânio e Afif são as opções da direita para a presidência. (1989, 27 de janeiro). In O Liberal (p. 19).

Jesus, C. G. N. (2006). Anti-semitismo e nacionalismo, negacionismo e memória. São Paulo, SP: Ed. Unesp.

Krischker, J. (2004). A extrema-direita americana no Brasil: ideologia, organização e práticas dos Larouchistas - a organização LaRouche. In L. MILMAN (Org.), Ensaios sobre o anti-semitismo contemporâneo: dos mitos e das críticas aos tribunais (pp. 75-91). Porto Alegre, RS: Sulina.

"Letras em Marcha” aponta comunização. (1986, 30 de setembro). In O Globo (p. 7).

Lopes, L. R. (1992). Do terceiro Reich ao novo nazismo. Porto Alegre, RS: Ed. UFRGS.

Mack, E. (1994, 30 de agosto). Admirador de Hitler decide apoiar Enéas. Recuperado de http://www1. folha.uol.com.br/fsp/1994/8/30/caderno_especial/19.html

Maitino, M. E. (2018). "Direita, sem vergonha”: conformações no campo da direita no Brasil a partir do discurso de Jair Bolsonaro. Plural: Revista do Programa de Pós-Graduação em Sociologia da USP, 25(1), 92-11.

Mann, M. (2008). Fascistas. São Paulo, SP: Record.

Momento decisivo. (1989, novembro). In Ombro a Ombro, 2(18), 1.

Motta, R. P. S. (2002). Em guarda contra o perigo vermelho: o anticomunismo no Brasil. São Paulo, SP: Perspectiva. 
Natali, J. B. (1986, 21 de dezembro). Integralistas tem timido "lobby" para a constituinte. Recuperado de https://www2.senado.leg.br/bdsf/bitstream/handle/id/116736/1986_DEZEMBRO_084b.pdf?

sequence $=1$ \&isAllowed $=\mathrm{y}$

Oliveira, P. C. (2014). Música, neofascismos e a nova história política: uma análise sobre a presença do Hate Rock no Brasil (1990-2010). Boletim Historiar, 6, pp, 43-56.

Partido de Ação Nacionalista. (1983, 28 de outubro). Manifesto Programa (ano 1, n. 1). São Paulo, SP: Autor.

Partido de Reedificação da Ordem Nacional - PRONA - Ata de Fundação. (1989, 6 de abril). In Diário Oficial da União (Seção I, pp. 5280-5285).

Pereira, M. H. F. (2015). Nova direita? Guerras de memória em tempos de Comissão da Verdade (2012-2014). Varia Historia, 31(57), 863-902.

Pierucci, A. F. (1987). As bases da nova direita. Novos Estudos (CEBRAP). n. 19, pp. 26-45.

Power, T. J. (2000). The political right in postauthoritarian Brazil: elites, institutions, and democratization. University Park, PA: Pennsylvania State University Press.

Quadros, M. P. R. \& Madeira, R. M. (2018). Fim da direita envergonhada? Atuação da bancada evangélica e da bancada da bala e os caminhos da representação do conservadorismo no Brasil. Opinião Pública, 24(3), 486-522.

Reis, D. A. (2010). Ditadura, anistia e reconciliação. Estudos Históricos (Rio de Janeiro), 23(45), 171-186.

Rocha, C. (2018). "Menos Marx, mais Mises": uma gênese da nova direita brasileira (2006-2018)

(Tese de Doutorado). Universidade de São Paulo, São Paulo, SP.

Santos, E. H. J. (2009). Extrema-direita, volver! Memória, ideologia e política dos grupos formados por civis e militares da reserva (Dissertação de Mestrado). Universidade Federal Fluminense,

Niterói, RJ.

Trindade, H. (2000). Fascismo e neofascismo na América Latina. In L. Milman (Org.), Neonazismo, negacionismo e extremismo político (pp. 47-75). Porto Alegre, RS: Ed. UFRGS.

Vale, I. (1994, 30 de junho). Carecas driblam nazismo com futebol e reggae. O Estado de São Paulo, p. G6.

Velasco e Cruz, S., Kaysel, A., \& Codas, G. (Orgs.). (2015). Direita, volver! O retorno da direita e o ciclo político brasileiro. São Paulo, SP: Ed. Fundação Perseu Abramo. 


\section{Para citar este artigo:}

Norma A - ABNT

CALDEIRA NETO, O. Neofascismo, "Nova República" e a ascensão das direitas no Brasil.

Conhecer: Debate entre o Público e o Privado, v. 10, n. 24, p. 120-140, 2020.

Norma B - APA

Caldeira, O.. Neto, (2020). Neofascismo, "Nova República” e a ascensão das direitas no Brasil.

Conhecer: Debate entre o Público e o Privado, 10(24), 120-140.

Norma C - Vancouver

Caldeira Neto O. Neofascismo, "Nova República" e a ascensão das direitas no Brasil.

Conhecer: Debate entre o Público e o Privado [Internet]. 2020 [cited Set 29, 2020];10(24):120-140.

Available from: https://revistas.uece.br/index.php/revistaconhecer/article/view/2060 